\section{Phyllosphere and carposphere bacterial communities in olive plants subjected to different cultural practices}

\author{
Silvia Pascazio, ${ }^{1}$ Carmine Crecchio, ${ }^{1}$ \\ Patrizia Ricciuti, ${ }^{1}$ Assunta Maria Palese, ${ }^{2}$ \\ Cristos Xiloyannis, ${ }^{2}$ Adriano Sofo ${ }^{3}$ \\ 1'Department of Soil, Plant and Food \\ Sciences, University of Bari, Aldo Moro; \\ 2Department of European and \\ Mediterranean Cultures: Architecture, \\ Environment and Cultural Heritage, \\ Basilicata University, Matera; ${ }^{3}$ School of \\ Agricultural, Forestry, Food and \\ Environmental Sciences, Basilicata \\ University, Potenza, Italy
}

\section{Abstract}

The aim of this study was to characterize phyllosphere and carposphere bacterial communities of olive trees subjected for 13 years to two different soil management systems (sustainable and conventional) in a mature olive grove located in Southern Italy. Amplified DNA fragments of the $16 \mathrm{~S}$ ribosomal RNA eubacterial gene (16S $r R N A)$ of bacteria living on leaf and fruit surface, and in fruit pulp were analyzed by denaturing gradient gel electrophoresis (DGGE). A clone library of $16 \mathrm{~S} r R N A$ amplicons extracted from the bacteria living in pulp homogenates and a phylogenetic analysis were performed. Generally, the DGGE patterns of the bacteria from both the treatments clustered separately. The medium-term sustainable orchard management resulted in a higher number of bacterial species from olive fruit pulp. Phyllosphere and carposphere communities evaluated by DGGE were affected by the type of the agricultural practices adopted. A better understanding of phyllosphere and carposphere microbiota of cultivated olive plants could be useful for the promotion of plant growth, a better plant protection and a higher crop quality.

\section{Introduction}

Leaf, flower and fruit represent a substantial multiple of the soil and plant surface area and often have complex topographical features on which microbial colonization can occur. ${ }^{1,2}$ The potential population size of microorganisms associated to these three additional surfaces can be impressive, exceeding by 100 to 1000 times that of soil. ${ }^{3,4}$ The aerial habitat part of plants for microorganisms, namely phyllosphere for leaves and carposphere for fruits, is normally colonized by a variety of bacteria, yeasts and fungi. Bacteria are by far the most numerous colonists, often being found at levels of $10^{6}-10^{7}$ cells $\mathrm{cm}^{-2}$ of leaf surface. ${ }^{4}$ Phyllosphere and carposphere are unique and dynamic habitats, with microbial communities subjected to irregular, and sometimes relatively large changes in temperature, UV radiation, relative humidity, nutrient availability upon the plant surface, and leaf wetness. ${ }^{5,6}$ Despite these environmental constraints, microorganisms flourish on both leaf and fruit surfaces, where they can also protect their hosts from disease or promote growth..$^{3-6}$

Leaf surface topography and nutrients are generally recognized as important regulators of phyllosphere microbial communities. Much of the interest in phyllosphere and carposphere microbiology has been driven by the need of better understanding the behavior and control of plant pathogens and the factors affecting food quality and safety. ${ }^{2,3}$ Phyllosphere microorganisms often also have a direct positive influence on plants, altering plant surface properties, enhancing nitrogen fixation, and promoting the growth of plants, the control of plant pathogens, and the degradation of organic pollutants. ${ }^{1,4}$

In semi-arid Mediterranean agricultural areas, soil degradation and water shortage phenomena are frequent and can have a strong negative impact on the agro-ecosystems and on food products. ${ }^{7}$ Thus, the adoption of sustainable soil and plant management practices, such as minimum tillage or no-till, recycling of locally derived organic matter and adequate irrigation, are urgently required to save water, restore soil organic matter, and reduce erosion and environmental pollution. ${ }^{8}$ In olive groves, the positive influence of sustainable management systems on soil microbiota has been described in the last decade. ${ }^{9-11}$ While the ecology of epiphyte microorganisms is both of scientific and economic importance, little research has been done on the changes phyllosphere and carposphere microbiota in response to the adoption of different cultural practices. On this basis, the aim of this study was to characterize phyllosphere and carposphere bacterial communities in olive trees subjected for a medium term (13 years) to two different orchard management systems, namely sustainable (S) and conventional (C), by using a combination of different culture-independent techniques including $16 \mathrm{~S} r R N A$ fingerprinting and cloning. On the basis of previous researches on soil microbiota carried out in the same system, ${ }^{8,11}$ we hypothesize that a sustainable soil and plant management could significantly affect the bacterial community composition of olive phyllosphere and carposphere.
Correspondence: Adriano Sofo, School of Agricultural, Forestry, Food and Environmental Sciences, Basilicata University, Viale dell'Ateneo Lucano 10, 85100 Potenza, Italy.

Tel.: +39.0971.206228.

E-mail: adriano.sofo@unibas.it

Key words: Bacterial diversity; carposphere; endophytic bacteria; Olea europaea L.; phyllosphere; sustainable soil management.

Contributions: SP, 16S rRNA fingerprinting; CC, fruit and leaf sampling and DNA extraction; PR, $16 \mathrm{~S}$ rRNA amplicons cloning and phylogenetic analysis; AMP, plant management; CX, soil management; AS, manuscript writing and statistical analysis.

Conflict of interest: the authors declare no potential conflict of interest.

Received for publication: 13 May 2015.

Revision received: 28 May 2015.

Accepted for publication: 28 May 2015.

This work is licensed under a Creative Commons Attribution NonCommercial 3.0 License (CC BYNC 3.0).

CCopyright et al., 2015

Licensee PAGEPress srl, Italy

International Journal of Plant Biology 2015; 6:6011 doi:10.4081/pb.2015.6011

\section{Materials and Methods}

\section{Experimental site and olive orchard management}

The trial was carried out in 2013 in a 2-ha mature ( $>50$ years) olive grove located in Southern Italy (Ferrandina, Basilicata Region, Italy; $40^{\circ} 29 \mathrm{~N}, 16^{\circ} 28 \mathrm{E}$ ). Trees belonged to Maiatica cultivar, an autochthonous olive variety for production of both table olives and olive oil, were vase-trained and planted at a distance of $8 \times 8 \mathrm{~m}$. The climate in the area is semi-arid, with an annual precipitation of $574.1 \mathrm{~mm}$ (mean 1976-2009) which falls mostly in the winter; the mean annual temperature ranges from 15 to $17^{\circ} \mathrm{C}$. The soil of the experimental grove is a sandy loam, a Haplic Calcisol with a mean bulk density of $1.5 \mathrm{t} \mathrm{m}^{-3}$. The top $60 \mathrm{~cm}$ of the soil had an average $\mathrm{pH}( \pm$ standard deviation) of $7.4 \pm 0.4$, an organic carbon content of $7.0 \pm 3.8 \mathrm{~g} \mathrm{~kg}^{-1}$, a total nitrogen content of $0.8 \pm 0.2 \mathrm{~g} \mathrm{~kg}^{-1}$ (Kjeldahl method), and extractable phosphorus (Olsen method) and potassium of $11.7 \pm 5.9$ and $104 \pm 70 \mathrm{mg} \mathrm{kg}^{-1}$, respectively.

In 2000, the olive orchard was divided into two 1-ha plots managed according to different orchard management systems: a sustainable (S) treatment and a conventional (C) treatment. The $\mathrm{S}$ treatment was irrigated with 
municipal wastewater treated by a pilot unit, as described by other authors. ${ }^{7,12}$ The reclaimed wastewater was generally distributed from May to October by drip irrigation (6 self-compensating drippers per tree, each delivering $8 \mathrm{~L} \mathrm{~h}^{-1}$ ). The annual irrigation volume was around $300 \mathrm{~mm}$. In the $\mathrm{S}$ treatment, soil was totally and permanently covered by spontaneous self-seeding weeds (mainly graminaceous and leguminosae) which were mowed at least twice a year and residues were left on the ground as mulch. Olive trees were pruned lightly each year, in order to improve fruiting potential by controlling the amount of fruiting wood and enhancing flower bud differentiation. Similarly to herbaceous residues, pruning residues (4.4 $\mathrm{t} \mathrm{ha}^{-1} \mathrm{yr}^{-1}$ organic carbon) were shredded and then left on the ground as mulch. The average amounts of mineral elements yearly distributed by the wastewater used for irrigation were around 60 $\mathrm{kg} \mathrm{ha} \mathrm{h}^{-1}$ for $\mathrm{N}$ and $\mathrm{K}$ and $3 \mathrm{~kg} \mathrm{ha}^{-1}$ for $\mathrm{P}^{7} \mathrm{An}$ integrative amount of $\mathrm{N}\left(40 \mathrm{~kg} \mathrm{ha}^{-1}\right.$ year $\left.^{-1}\right)$ was distributed by fertirrigation, in order to entirely satisfy the annual N plant needs, taking into account wastewater and soil chemical composition, and mineral element balance in the orchard system (cover crops and pruning material contributions, amount of fruit removed from the olive grove). Pest and disease control was performed according to the regional service recommendations for commercial olive groves. ${ }^{7,13}$ The olives from the $\mathrm{C}$ treatment were grown under rainfed conditions and managed according to the traditional and horticultural practices of the area usually adopted by the farmers, ${ }^{13}$ that is: tillage (milling at $10 \mathrm{~cm}$ depth) performed 2-3 times per year to control weeds; empirical soil fertilization carried out in early spring using ternary compounds (NPK 20-10-10 fertilizer at doses ranging from 300 to $500 \mathrm{~kg} \mathrm{ha}^{-1}$ ), without considering the plant needs and their partitioning along the various phenological phases of the annual vegetative cycle; and severe pruning carried out every two years, with pruned residues removed from the olive orchard. After 13 year of different management, the $\mathrm{S}$ practices resulted in an increase of soil organic carbon in the $0-10 \mathrm{~cm}$ soil layer up to $22.1 \mathrm{~g} \mathrm{~kg}^{-}$ , compared to $11.8 \mathrm{~g} \mathrm{~kg}^{-1}$ of the $\mathrm{C}$ treatment.

\section{Leaf and fruit collection and sam- ple preparation}

In November 2013, leaves and olive fruits were collected in both the treatments ( $\mathrm{S}$ and C). For each treatment, two composite leaf and fruit samples were randomly collected using sterile gloves and equipment from plants located at the central part of each plot, in order to avoid border interferences. Fully expanded leaves and well-developed fruits selected from each plant along the median segment of newgrowth shoots, with similar light exposition and position in the canopy, were chosen. Leaf samples, placed at approximately $1.0 \mathrm{~m}$ from the drippers (for the $\mathrm{S}$ treatment) and at $1.5 \mathrm{~m}$ from the ground, were collected. Leaf and fruit samples were stored immediately at $4^{\circ} \mathrm{C}$ in sterilized plastic pots before analysis. In order to desorb bacteria from leaf (leaf; L) and fruit surface (pericarp; P), the method of Redford and Fierer was used, ${ }^{14}$ starting from 40 leaves (L) or 20 olives (P), respectively. In order to extract bacteria from fruit pulp (mesocarp; M), the same 20 olives were homogenized with 40 ml of sterilized Ringer solution, and the homogenate was then filtered under sterile conditions. The wash solution and the filtrate were centrifuged at $4000 \mathrm{rpm}$ for $10 \mathrm{~min}$ at $4^{\circ} \mathrm{C}$. The supernatant was discarded, and the resulting pellet was used for DNA extraction.

\section{DNA extraction}

DNA was extracted from $0.50 \mathrm{~g}$ of pellet using the FastDNA® SPIN Kit for soil in combination with the Thermo Savant FastPrep ${ }^{\circledR}$ System homogenizer (MP Biomedicals LLC, Cleveland, OH, USA). The yield and fragmentation of the DNA were checked by agarose gel electrophoresis $(0.7 \% \mathrm{w} / \mathrm{v}$ agarose- 0.5 xTrisBorate-EDTA) and UV visualization of the stained gels Gel $\operatorname{Red}^{\mathrm{TM}}$ (Biotium, Inc., Hayward, CA, USA). The quality and concentration of DNA extracts were determined by spectrophotometric measurement at 260,280 and $230 \mathrm{~nm}$ using a NanoDrop ${ }^{\circledR} \mathrm{ND}-1000$ UV-Vis spectrophotometer (Thermo Fisher Scientific, Inc., Waltham, MA, USA).

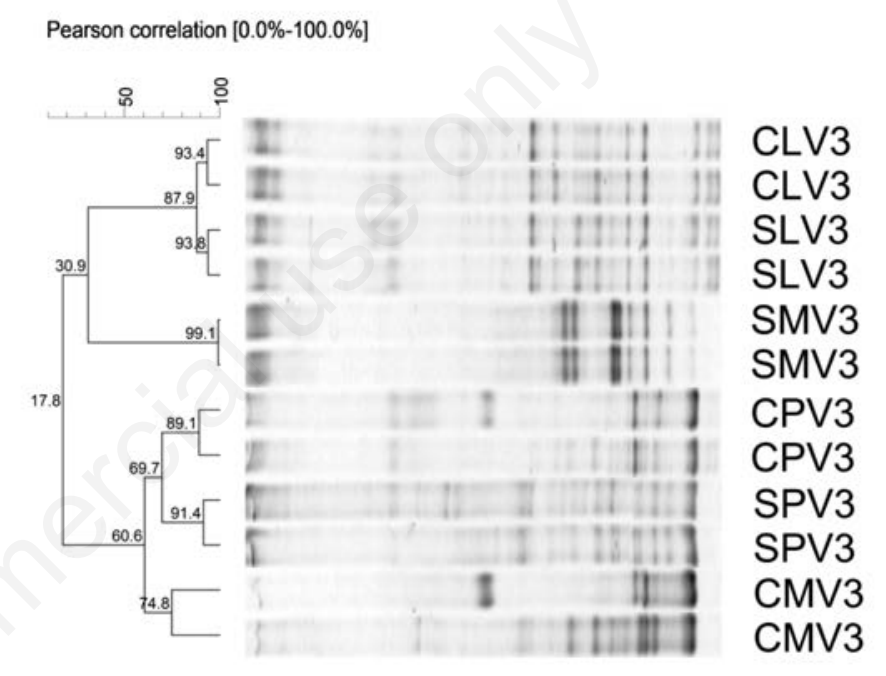

Pearson correlation $[0.0 \%-100.0 \%]$

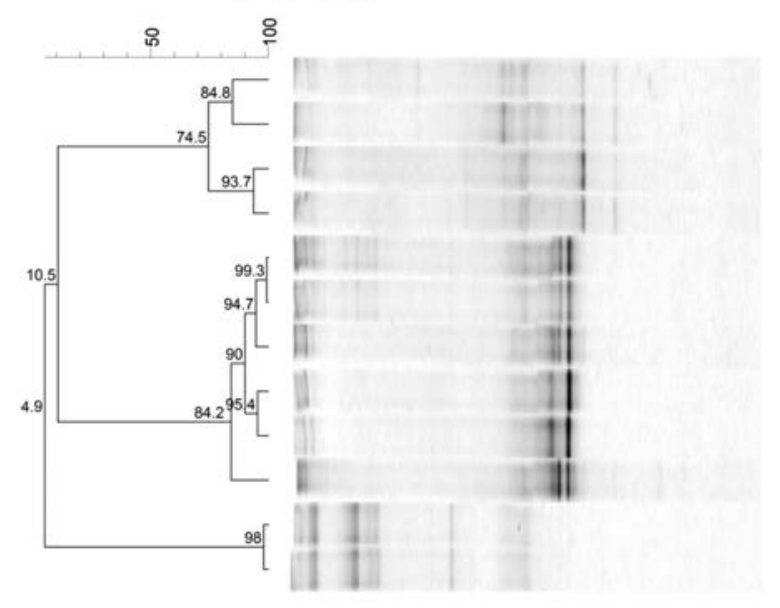

SLV6-V8

SLV6-V8

CLV6-V8

CLV6-V8

SPV6-V8

SPV6-V8

CPV6-V8

CMV6-V8

CMV6-V8

CPV6-V8

SMV6-V8

SMV6-V8

Figure 1. 16S denaturing gradient gel electrophoresis fingerprints $(n=2)$ of phyllosphere and carposphere bacterial communities of olive plants based on the amplification of the V3 region (A) and V6-V8 region (B) of the small subunit $r R N A$ eubacterial gene. Clustering was carried out using the UPGMA method based on the Pearson correlation coefficient. S: sustainable, C: conventional, L: leaf surface, P: pericarp surface, M: mesocarp. 


\section{S rRNA fingerprinting by PCR-}

\section{DGGE}

DNA fragments in the V3 and V6-V8 regions of the $16 \mathrm{~S}$ ribosomal RNA eubacterial gene (16S $r R N A$ ) were amplified by using the primer sets F357-R518 and 968F-1401R, ${ }^{15,16}$ respectively. For separating the $16 \mathrm{~S}$ rRNA bacterial communities in a DGGE gel, a GC clamp was added at the end of the primer F357 and 968F.Each PCR mixture contained 50 pmol of each primer, $10 \mathrm{nmol}$ of each 2'-deoxynucleoside 5'-triphosfate, $3 \mathrm{U}$ of Taq DNA polymerase (EuroTaq; EuroClone, Milan, Italy), $2.5 \mathrm{mM}$ $\mathrm{MgCl}_{2}$, and 20-40 ng of template DNA. All PCR amplifications were performed using a MyCycler $^{\mathrm{TM}}$ thermal cycler (Bio-Rad Laboratories, Inc., Hercules, CA, USA). Amplification products were checked by electrophoresis on $1.5 \%(\mathrm{w} / \mathrm{v})$ agarose gels.

PCR products were then loaded onto dena- turing gradients. The region V3 and V6-V8 regions, were separated, respectively, in a $8 \%$ and $6 \%(\mathrm{w} / \mathrm{v})$ polyacrylamide gels (acrylamide $N, N$-methylnebisacrylamide, w/w, 37.5:1) in $1 \times$ TAE buffer with a linear chemical denaturing gradient ranging from $25-50 \%$ and $45-60 \%$ denaturant, respectively. Electrophoresis was carried out at $60^{\circ} \mathrm{C}$ for $10 \mathrm{~min}$ at $20 \mathrm{~V}$ and then for $3 \mathrm{~h}$ at $200 \mathrm{~V}$ for the $\mathrm{V} 3$ region, and for $15 \mathrm{~h}$ at $75 \mathrm{~V}$ for theV6-V8 region, using the method

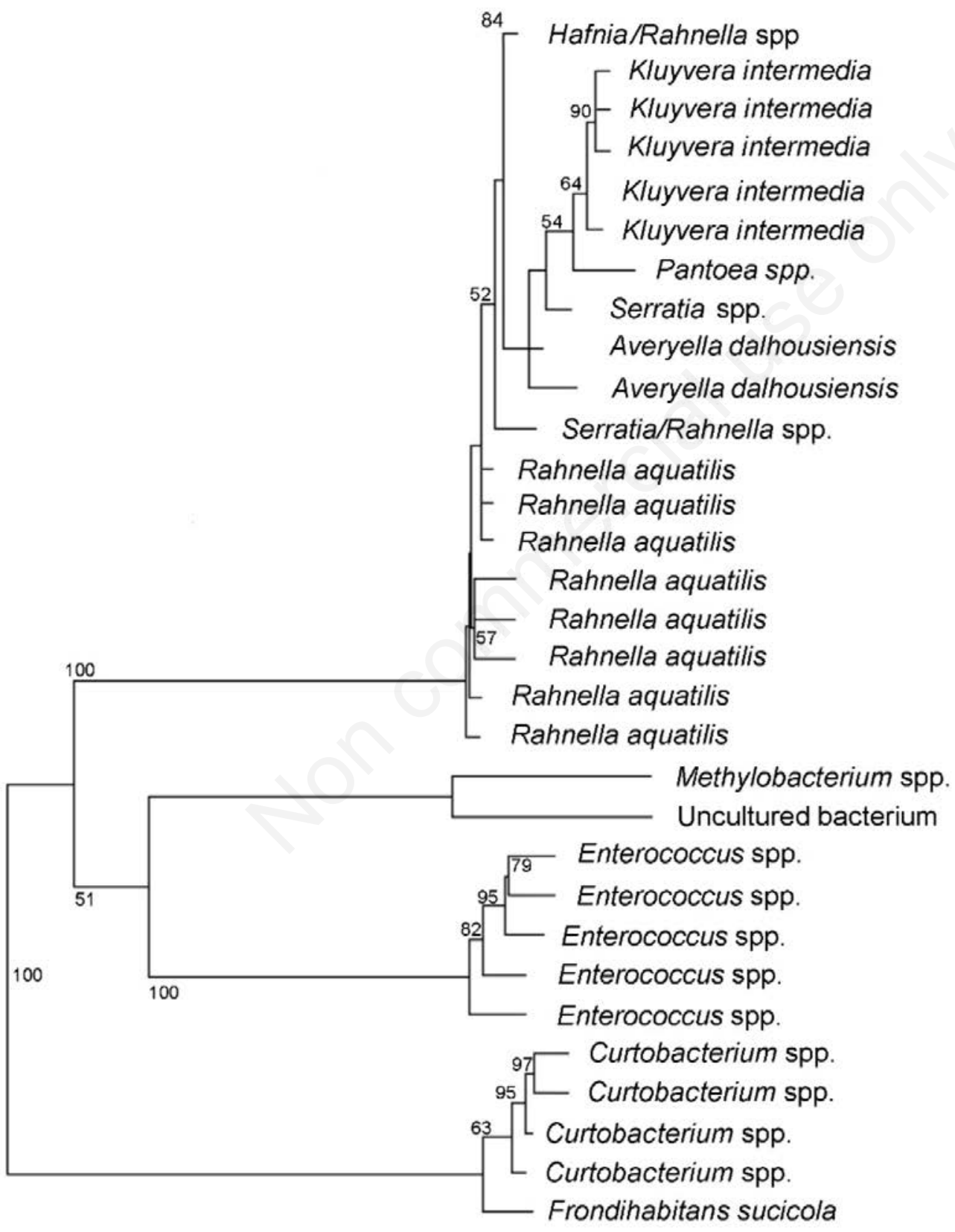

Figure 2. Phylogenetic tree of $16 \mathrm{~S} r R N A$ sequences of bacteria isolated from olive mesocarp of the sustainable treatment. Clustering was carried out using the maximum likelihood method. The branches are scaled in terms of the expected number of substitutions per site (scale bar $=0.1$ substitutions per nucleotide position). Numbers adjacent to the branches are support values from $100 \mathrm{ML}$ bootstrap replicates. Bootstrap values $\geq 50$ are shown. 
of Crecchio et al. ${ }^{17}$ DGGE profiles comparison and bacterial phylogenetic tree were constructed using the BioNumerics software (version 4.5; Applied Maths, Sint-Martens-Latem, Belgium) by the unweighted pair-group method with the arithmetic average clustering algorithm (UPGMA) based on the Pearson product-moment correlation coefficient $(r)$.

\section{S rRNA amplicons cloning and phylogenetic analysis}

A clone library was constructed using DNA extracted from fruit homogenates. The total region $16 \mathrm{~S} r R N A$ was amplified with the universal primer for bacteria 8L-1513R. ${ }^{18}$ The clone library was generated by ligating PCR products into the pGEM-T (Promega; Madison, WI, USA), which were then transformed into competent Escherichia coli JM109 cells. A number of 100 clones from mesocarp of the sustainable treatment and from the mesocarp of the conventional treatment, containing the insert of the correct size were sequenced (Primm Biotech, Inc., Milano, Italy) for both strands with the primer 357F-1401R. ${ }^{19}$ The resultant sequences were aligned to the NCBI database using BLASTn (NCBI BLAST ${ }^{\circledR}$; National Center for Biotechnology Information, Bethesda, MD, USA). These sequences were aligned separately or as a concatenated matrix using the multiple sequence alignment software ClustalW2 (EMBL-EBI, European Bioinformatics Institute, Cambridge, UK). Phylogenetic trees were carried out using a multiplatform graphical user interface for sequence alignment and phylogenetic tree building (SeaView, version 4) using the maximum likelihood (ML) method. ${ }^{20}$

\section{Results and Discussion}

In our work, the bacterial communities of the phyllosphere of the $\mathrm{S}$ treatment (SLV3) were discriminated from the patterns of the phyllosphere of the $\mathrm{C}$ treatment (CLV3), with a Pearson similarity coefficient of $87.9 \%$ (Figure 1A). The DGGE patterns of the bacteria of pericarp surface (SPV3 and CPV3) highlighted a clear separation between sustainable (S) and conventional (C) treatments and clustered separately at a lower value of similarity (69.7\%), compared to phyllosphere (Figure 1A). The DGGE fingerprints showed a clear discrimination between $\mathrm{S}$ and $\mathrm{C}$ sites for mesocarp bacteria, with a Pearson similarity coefficient of only $17.8 \%$ (Figure 1A). The DGGE dendrogram of bacterial 16S DGGE fingerprint based on the amplification of the V6V8 region paralleled that obtained by the amplification of the $\mathrm{V} 3$ region, evidencing that the $\mathrm{S}$ treatment clustered separately from the C treatment for phyllosphere, pericarp surface and mesocarp bacteria, with Pearson similarity coefficient values $74.5,84.2$ and $4.9 \%$, respectively (Figure 1B). DGGE was successfully used to evaluate the influence of various plant genotypes, and the inoculation of the nitrogen-fixing bacterium Azospirillum brasilense upon the epiphyte community of tomato phyllosphere. ${ }^{21}$ Such DGGE-based methods for studying phyllosphere microbial communities also included quantitative PCR to estimate the abundance of specific bacterial taxa on a plant, rRNA gene amplicon pyrosequencing to assess fungal and bacterial abundance/diversity on tree foliage, and proteogenomics to uncover the most abundantly expressed genes in the phyllosphere environment. $^{1}$

The electrophoretic profiles relative to both V3 and V6-V8 regions of $16 \mathrm{~S} r R N A$ showed that the bacterial communities of fruit mesocarp of both $\mathrm{S}$ and $\mathrm{C}$ treatments clustered at higher values of Pearson correlation coefficient, compared to those of fruit or leaf surfaces (Figure 1). On this basis, we decided to study in detail the bacteria present in olive mesocarp. The classification of the bacterial groups isolated from olive fruit pulp (mesocarp) and the corresponding phylogenetic analysis are reported in Table 1 and Figure 2, respectively. Sequence homology search for the bacteria living in mesocarp of the sustainable treatment revealed 70 sequences of olive chloroplast genome and 30 belonging to bacterial genomes. For the mesocarp bacteria of $\mathrm{C}$ treatment, most of the sequences (98) derived from olive chloroplasts and only two belonged to bacterial genomes. The results showed that the DNA sequences (identity $\geq 97 \%$ ) of the bacteria isolated from olive mesocarp belonged to the phyla the Proteobacteria, Actinobacteria, Firmicutes, with sequences of Proteobacteria being the most abundant ( 20 and 2 species in $\mathrm{S}$ and C, respectively) (Table 1). The data on the bacterial groups isolated from olive fruit pulp (mesocarp), identified on the basis of their genomic sequences (Table 1 and Figure 2), reflected the results found by other authors on phyllosphere bacteria of tree species of temperate and tropical regions, ${ }^{14}$ and of herbaceous species. ${ }^{5}$ In our experiment, the most abundant bacteria belonged to the family Enterobacteriaceae (19 and 2 species in $\mathrm{S}$ and $\mathrm{C}$, respectively) (Table 1). This result is not surprising, considering their massive presence on the aerial surfaces of plants and within healthy plant tissues and seeds. ${ }^{6}$ Interestingly, insects can play an important role in the composition of plant-associated bacterial communities. For instance, many species of plant bacteria uses flies or other insects as vectors, ${ }^{22}$ even if it is not always clear if bacterial strains found in the insect digestive tract originate from plants (as for Serratia spp.) or it is the opposite (as for Enterococcus spp.). ${ }^{23,24}$ Leff and Fierer demonstrated, ${ }^{6}$ by $16 \mathrm{~S}$ rRNA pyrosequencing that some fruits and vegetables harbored different bacterial communities. Some products showed a higher number of bacteria belonging to the family Enterobacteriaceae, while some other

Table 1. Classification of the bacterial species from olive fruit pulp (mesocarp) identified on the basis of their genomic sequences (NCBI BLAST® hits).

\begin{tabular}{|c|c|c|c|c|c|c|}
\hline N. species & Phylum & Class & Order & Family & Genus & Species \\
\hline \multicolumn{7}{|l|}{ Sustainable } \\
\hline 8 & Proteobacteria & $\gamma$-Proteobacteria & Enterobacteriales & Enterobacteriaceae & Rahnella & aquatilis \\
\hline 5 & Firmicutes & Bacilli & Lactobacillales & Enterococcaceae & Enterococcus & unknown \\
\hline 5 & Proteobacteria & $\gamma$-Proteobacteria & Enterobacteriales & Enterobacteriaceae & Kluyvera & intermedia \\
\hline 4 & Actinobacteria & Actinobacteridae & Actinomycetales & Microbacteriaceae & Curtobacterium & unknown \\
\hline 2 & Proteobacteria & $\gamma$-Proteobacteria & Enterobacteriales & Enterobacteriaceae & Averyellaa & dalhousiens \\
\hline 1 & Actinobacteria & Actinobacteridae & Actinomycetales & Microbacteriaceae & Frondihabitans & suicicola \\
\hline 1 & Proteobacteria & $\gamma$-Proteobacteria & Enterobacteriales & Enterobacteriaceae & Hafnia/Rahnella & alvei \\
\hline 1 & Proteobacteria & $\alpha$-Proteobacteria & Rhizobiales & Methylobacteriaceae & Methylobacterium & unknown \\
\hline 1 & Proteobacteria & Y-Proteobacteria & Enterobacteriales & Enterobacteriaceae & Pantoea & unknown \\
\hline 1 & Proteobacteria & Y-Proteobacteria & Enterobacteriales & Enterobacteriaceae & Serratia/Rahnella & unknown \\
\hline 1 & Proteobacteria & $\gamma$-Proteobacteria & Enterobacteriales & Enterobacteriaceae & Serratia & unknown \\
\hline \multicolumn{7}{|l|}{ Conventional } \\
\hline 2 & Proteobacteria & $\gamma$-Proteobacteria & Enterobacteriales & Enterobacteriaceae & Pantoea & agglomerans \\
\hline
\end{tabular}


products had higher abundance of Actinobacteria, Bacteroidetes, Firmicutes, and Proteobacteria phyla. They also stated that conventionally and organically farmed varieties could contribute to the variations in the bacterial communities. Unfortunately, these authors did not sample plant material directly from the field, following all the steps of production and deeply monitoring soil and plant management, but they studied the commercial product found on the market, that were likely affected by other variable, such as storage type and time.

Given that large volumes of water are needed for irrigation in tree crops, water demand cannot always be met with the available potable water. The type of irrigation system can influence the risk of crop contamination: overhead irrigation, for instance, usually causes more microbial contamination than furrow and drip irrigation. ${ }^{25}$ In our case, this risk was avoided, as the bacterial species found in the $S$ treatment (Table 1 and Figure 2) were completely different from those monitored and found at very low concentrations by Palese $e t$ $a .^{7}$ (total coliforms, fecal coliforms, Escherichia coli, and Salmonella spp.) in the same system. Therefore, the risk of soil contamination in $\mathrm{S}$ treatment by such bacteria deriving from wastewater, that then eventually translates into fruit contamination, can be considered negligible. ${ }^{7,12}$

\section{Conclusions}

Our results demonstrated that a mediumterm sustainable orchard management determined a higher number of bacterial species from olive fruit pulp (mesocarp), identified on the basis of their genomic sequences. Moreover, phyllosphere and carposphere communities evaluated by DGGE were altered by the application of the two different agricultural practices. A better understanding of epiphytic and endophytic microbiota of cultivated olive plants grown under different agronomic systems could be useful for the promotion of plant growth, a better plant protection and a higher crop quality.

\section{References}

1. Meyer KM, Leveau HHJ. Microbiology of the phyllosphere: a playground for testing ecological concepts. Oecologia 2012;168:621-9.

2. Vorholt JA. Microbial life in the phyllosphere. Nat Rev Microb 2012;10:828-40.

3. Lindow SE, Brandl MT. Microbiology of the phyllosphere. Appl Environ Microb 2003;69:1875-83.

4. Xie WY, Su JQ, Zhu YG. Phyllosphere bacterial community of floating macrophytes in paddy soil environments as revealed by illumina high-throughput sequencing. Appl Environ Microb 2015;81:522-53.

5. Delmotte N, Knief C, Chaffron S, et al. Community proteogenomics reveals insights into the physiology of phyllosphere bacteria. Proc Natl Acad Sci USA 2009;26:16428-33.

6. Leff JW, Fierer N. Bacterial communities associated with the surfaces of fresh fruits and vegetables. PLoS One 2013;8:e59310.

7. Palese AM, Pasquale V, Celano G, et al. Irrigation of olive groves in Southern Italy with treated municipal wastewater: effects on microbiological quality of soil and fruits. Agric Ecosyst Environ 2009;129:4351.

8. Sofo A, Ciarfaglia A, Scopa A, et al. Soil microbial diversity and activity in a Mediterranean olive orchard managed by a set of sustainable agricultural practices. Soil Use Manage 2014;30:160-7.

9. Benitez E, Nogales R, Campos M, et al. Biochemical variability of olive-orchard soils under different management systems. Appl Soil Ecol 2006;32:221-31.

10. Moreno B, Garcia-Rodriguez S, Cañizare $\mathrm{R}$, et al. Rainfed olive farming in southeastern Spain: long-term effect of soil management on biological indicators of soil quality. Agric Ecosyst Environ 2009;131:333-9.

11. Sofo A, Palese AM, Casacchia T, et al. Genetic, functional, and metabolic responses of soil microbiota in a sustainable olive orchard. Soil Sci 2010;175:81-8.

12. Lopez A, Pollice A, Lonigro A, et al. Agricultural wastewater reuse in Southern Italy. Desalination 2006;187:323-34.

13. Xiloyannis C, Martinez Raya A, Kosmas C, et al. Semi-intensive olive orchards on sloping land: requiring good land husbandry for future development. J Environ Manage 2008;89:110-9.

14. Redford AJ, Fierer N. Bacterial succession on the leaf surface: a novel system for studying successional dynamics. Microb Ecol 2009;58:189-98.

15. Temmerman R, Scheirlinck I, Huys G, et al.
Culture-independent analysis of probiotic products by denaturing gradient gel electrophoresis. Appl Environ Microb 2003;69:220-6.

16. Heuer H, Smalla K. Application of denaturing gradient gel electrophoresis and temperature gradient gel electrophoresis for studying soil microbial communities. In: van Elsas JD, Wellington EMH, eds. Modern soil microbiology. New York: Marcel Dekker, 1997. pp 353-273.

17. Crecchio C, Curci M, Mininni R, et al. Short-term effects of municipal solid waste compost amendments on soil carbon and nitrogen content, some enzyme activities and genetic diversity. Biol Fert Soils 2001;34:311-8.

18. Wang GCY, Wang Y. Frequency of formation of chimeric molecules as a consequence of PCR coamplification of $16 \mathrm{~S}$ rRNA genes from mixed bacterial genomes. Appl Environ Microb 1997;63:4645-50.

19. Yu Z, Morrison M. Comparisons of different hypervariable regions of rrs genes for use in fingerprinting of microbial communities by PCR-denaturing gradient gel electrophoresis. Appl Environ Microb 2004;70:4800-6.

20. Gouy M, Guindon S, Gascuel 0. SeaView Version 4: a multiplatform graphical user interface for sequence alignment and phylogenetic tree building. Mol Biol Evol 2010;27:221-4.

21. Correa OS, Romero AM, Montecchia MS, et al. Tomato genotype and Azospirillum inoculation modulate the changes in bacterial communities associated with roots and leaves. J Appl Microb 2007;201:781-6.

22. Kuzina LV, Peloquin JJ, Vacek DC, et al. Isolation and identification of bacteria associated with adult laboratory Mexican fruit flies, Anastrephaludens (Diptera: Tephritidae). Curr Microb 2001;42:290-4.

23. Devriese L, Baele M, Butaye P. The Genus Enterococcus: taxonomy. Prokaryotes 2006;4:163-74.

24. Kado CI. Erwinia and related genera. Prokaryotes 2006;6:443-50.

25. Telias A, White JR, Pahl DM, et al. Bacterial community diversity and variation in spray water sources and the tomato fruit surface. BMC Microbiol 2011;11:81. 